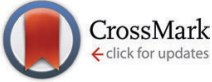

Cite this: Phys. Chem. Chem. Phys., 2015, 17, 11350

Received 13th January 2015, Accepted 16th March 2015

DOI: $10.1039 / c 5 c p 00194 c$

www.rsc.org/pccp

\section{Internal heavy atom effects in phenothiazinium dyes: enhancement of intersystem crossing via vibronic spin-orbit coupling $\dagger$}

\author{
Angela Rodriguez-Serrano, ${ }^{a b}$ Vidisha Rai-Constapel, ${ }^{c}$ Martha C. Daza, ${ }^{a}$ \\ Markus Doerr*a and Christel M. Marian*c
}

\begin{abstract}
The effect of substituting the intra-cyclic sulphur of thionine by oxygen (oxonine) and selenium (selenine) on the intersystem crossing (ISC) efficiency has been studied using high level quantum mechanical methods. The ISC rate constants are considerably increased when going from O towards Se while the fluorescence rate constants remain unchanged. For the three dyes, all accessible ISC channels are driven by vibronic spin-orbit coupling (SOC) between $\pi \pi^{\star}$ states. The interplay between the ground and low-lying excited states has been investigated in order to determine the dominant relaxation pathways. In oxonine the relaxation to the ground state after photoexcitation in water proceeds essentially via fluorescence from the $S_{1}\left(\pi_{H} \pi_{\mathrm{L}}{ }^{*}\right)$ bright state $\left(k_{\mathrm{F}}=2.10 \times 10^{8} \mathrm{~s}^{-1}\right)$, in agreement with the high experimental fluorescence quantum yield. In aqueous solution of thionine, the ISC rate constant $\left(k_{\text {ISC }} \sim 1 \times 10^{9} \mathrm{~s}^{-1}\right)$ is one order of magnitude higher than fluorescence $\left(k_{\mathrm{F}}=1.66 \times 10^{8} \mathrm{~s}^{-1}\right)$ which is consistent with its high triplet quantum yield observed in water $\left(\phi_{\mathrm{T}}=0.53\right)$. Due to a stronger vibronic SOC in selenine, the ISC rate is very high $\left(k_{\text {ISC }} \sim 10^{10} \mathrm{~s}^{-1}\right)$ and much faster than fluorescence $\left(k_{\mathrm{F}}=1.59 \times\right.$ $10^{8} \mathrm{~s}^{-1}$ ). This suggests selenine-based dyes as very efficient triplet photosensitizers.
\end{abstract}

\section{Introduction}

Phenothiazinium dyes are the basis of many chromophores useful in chemistry and biology. ${ }^{1,2}$ These chromophores are widely used for cellular staining, ${ }^{3}$ for the decontamination of blood products, ${ }^{4}$ as redox biosensors, ${ }^{5}$ as fluorescent labels, ${ }^{6}$ and as antimicrobials. ${ }^{7}$ Some of these photosensitizers have potential application in photodynamic therapy (PDT).$^{8,9}$ A prerequisite for a potent photosensitizer is the existence of a longlived triplet excited state and its efficient population via intersystem crossing (ISC). Singlet oxygen $\left({ }^{1} \mathrm{O}_{2}\right)$ is photochemically produced by energy transfer from such a triplet state of the photosensitizer. The ${ }^{1} \mathrm{O}_{2}$ thus produced initiates the programmed cell death (apoptosis). ${ }^{10}$ In this framework, new dyes have been

\footnotetext{
${ }^{a}$ Grupo de Bioquímica Teórica, Universidad Industrial de Santander, Carrera 27, Calle 9, Bucaramanga, Colombia. E-mail: markusdoerr@gmx.de

${ }^{b}$ Grupo de Fotodinámica Molecular, Departamento de Química,

Universidad de los Andes, Carrera 1 No. 18A-10, Bogotá, Colombia

${ }^{c}$ Institute of Theoretical and Computational Chemistry, Heinrich Heine University

Düsseldorf, Universitätsstr. 1, D-40225 Düsseldorf, Germany.

E-mail: Christel.Marian@hhu.de

$\dagger$ Electronic supplementary information (ESI) available: The equilibrium geometries of the ground and excited states of oxonine and selenine, together with their TDDFT adiabatic energies, results regarding to the basis set choice of oxonine and the dependence of the computed intersystem crossing rate constants on technical computational parameters. See DOI: 10.1039/c5cp00194c
}

recently synthesized taking advantage of their structural properties and focusing in the design of more efficient singlet oxygen photosensitizers. $^{1-11}$

The inclusion of heavy atoms in the molecular structure increases the spin orbit coupling (SOC) between singlet and triplet states, which may lead to more efficient ISC. These effects have been tested in phenothiazinium dyes with respect to the singlet oxygen quantum yield $\left(\phi_{\Delta}\right)$. The peripheral inclusion of bromine or iodine in the related $O$-methyl methylene violet chromophore results in a significant rise of $\phi_{\Delta},{ }^{12}$ but decreases its solubility in water. ${ }^{2-4}$ Substitution of oxygen in tetramethylrosamine and benzo[ $a]$ phenoxazine dyes by sulphur and selenium has resulted in a significant rise in $\phi_{\Delta}$ and small spectral shifts in the absorption and emission spectra. ${ }^{13,14}$ Motivated by these observations, we investigated how such internal heavy atom effects could influence the photophysics of the simplest phenothiazinium chromophore.

Thionine (3,7-diamino-phenothiazin-5-ium cation, see Fig. 1) is the smallest and structurally representative compound of the phenothiazinium dyes $\left(\phi_{\Delta} \sim 0.5\right){ }^{8,15,16}$ The replacement of the central ring sulphur of thionine $(\mathrm{X}=\mathrm{S})$ by oxygen and selenium gives oxonine $(\mathrm{X}=\mathrm{O})$ and selenine $(\mathrm{X}=\mathrm{Se})$, respectively (see Fig. 1). These three compounds show similar spectral properties in the ground and in the triplet states. ${ }^{17}$ Oxonine (also known as oxazine 118) has an absorption maximum at $578 \mathrm{~nm}^{18}$ and a 


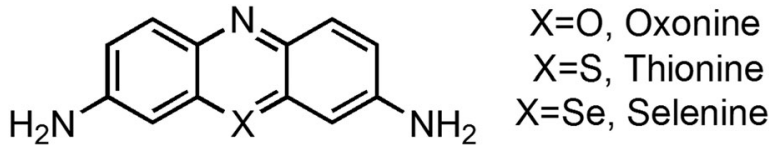

Fig. 1 Chemical structure of thionine and its heteroanalogues.

triplet transient absorption band at $780 \mathrm{~nm}^{19}$ in aqueous solution, while the corresponding maxima for thionine are located at $\sim 600 \mathrm{~nm}$ and $780-800 \mathrm{~nm}$, respectively. ${ }^{20}$ The substitution of $\mathrm{S}$ by $\mathrm{O}$ leads to an increased fluorescence yield in water $\left(\phi_{\mathrm{F}}=1.00\right.$, $\left.\tau_{\mathrm{F}}=3.2 \mathrm{~ns}\right)^{18}$ corresponding to the strongly decreased ISC rate $\left(k_{\mathrm{ISC}} \sim 7.2 \times 10^{5} \mathrm{~s}^{-1}, \phi_{\mathrm{T}} \sim 1.7 \times 10^{-3}\right) .{ }^{19}$ These photophysical properties make the oxazinium fluorophores suitable as laser dyes and optical sensors. ${ }^{21}$ Although this trend is known for the $\mathrm{X}=\mathrm{O}$ and $\mathrm{S}$ pair, similar experimental observations for selenine are not available.

In our previous work ${ }^{22,23}$ we studied in detail the photophysics of thionine in vacuum and aqueous environment. The efficient ISC in aqueous solution was found to proceed via the $\mathrm{S}_{1}\left(\pi_{\mathrm{H}} \pi_{\mathrm{L}}{ }^{*}\right) \rightsquigarrow \mathrm{T}_{2}\left(\pi_{\mathrm{H}-1} \pi_{\mathrm{L}}{ }^{*}\right)$ channel and the computed rate constants were in excellent agreement with experiment. In this paper, we throw light on the variation of the photophysics of thionine with respect to substitution of the intracyclic sulphur by oxygen and selenium. To this end, we have examined the energy interplay of the lowest excited states as well as the SOC and ISC rate constants in the series.

\section{Methods and computational details}

The geometry optimizations of the electronic states of oxonine and selenine have been performed at the level of density functional theory (DFT) for the ground state and time-dependent density functional theory (TDDFT) ${ }^{24}$ for the excited states. The B3LYP functional ${ }^{25,26}$ was used as implemented in Turbomole 6.3. ${ }^{27}$ As long as not stated otherwise, $C_{2 \mathrm{v}}$ symmetry constraints have been imposed for the optimization of the electronic ground and excited states. The Cartesian coordinate system was chosen in a way that the $x z$ plane coincides with the molecular plane and the $C_{2}(y)$ axis passes through the central-ring system. Harmonic vibrational frequencies were computed numerically employing the SNF program. ${ }^{28}$ The technical details of the methods used for the calculation of the electronic state geometries and properties of thionine can be found in our previous work. ${ }^{22}$ The characterization of the electronic state minima of selenine and thionine ${ }^{22}$ was performed using the TZVP basis set. ${ }^{29}$ Due to technical reasons the $\mathrm{SV}(\mathrm{P})$ basis set was used for the geometry optimization of the electronic states of oxonine, for details see the ESI. $\dagger$

The vertical $\left(\Delta E_{\mathrm{vac}}\right)$ and adiabatic $\left(\Delta E_{\mathrm{vac}}^{\mathrm{ad}}\right)$ excitation energies, (transition) dipole matrix elements and oscillator strengths were obtained from single-point calculations performed at each electronic state minimum at the density functional theory/ multi-reference configuration interaction (DFT/MRCI) level. ${ }^{30}$ In this semi-empirical method, the dynamic electron correlation is treated by DFT and the static electron correlation is accounted for via MRCI. This approach has been shown to yield reliable excitation energies and transition moments at a reasonable cost for a variety of closed-shell organic systems with errors typically less than $0.2 \mathrm{eV} .^{31,32}$ Technical details of the DFT/ MRCI calculations were chosen to be identical to those for thionine. ${ }^{22}$ Additionally, potential energy profiles along linearly interpolated pathways connecting the minima of the electronically excited states were computed. The adiabatic energies were calculated relative to the ground state energy at the ground state minimum.

To understand the possible deactivation channels in aqueous solution, the conductor-like screening model (COSMO, $\left.{ }^{33,34} \varepsilon=78\right)^{35}$ has been employed. Several models consisting of the solute and one to five water molecules with additional embedding in a COSMO environment were tested for simulating the hydrogen bonding effects. As already found for thionine (ref. 22), the best solvation model including three specific water molecules $\left(\mathrm{TH}^{+} 3 \mathrm{Wa}\right)$ was also found to be appropriate in this work $\left(\mathrm{OXH}^{+} 3 \mathrm{Wa}\right.$ and $\left.\mathrm{SEH}^{+} 3 \mathrm{Wa}\right)$. For calculating the DFT/MRCI vertical excitation energies of these dyewater clusters applying COSMO $\left(\Delta E_{\mathrm{w}}\right)$, the MRCI expansion was built up from the one-particle basis of the COSMO optimized KohnSham orbitals. The adiabatic excitation energies in aqueous solution $\left(\Delta E_{\mathrm{w}}^{\mathrm{ad}}\right)$ were calculated by applying the corresponding hydration shifts experienced by each state at the ground state minima of the dye-water models to the adiabatic energies of the respective excited states computed in vacuum $\left(\Delta E_{\text {vac }}^{\text {ad }}\right)$.

The electronic SOC matrix elements $\left(\left\langle\mathrm{S}_{a}\left|\hat{H}_{\mathrm{SO}}\right| \mathrm{T}_{b}^{\alpha}\right\rangle\right.$, SOMEs $)$ for the corresponding correlated DFT/MRCI wave functions were evaluated using the SPOCK program. ${ }^{36,37}$ The one-center meanfield Hamiltonian employed in these calculations is a nonempirical effective one-electron operator that treats the expensive two-electron terms of the full Breit-Pauli Hamiltonian in a Focklike manner. ${ }^{38}$ Attention has been centered on the vibronic SOC between the low-lying singlet and triplet $\left(\pi \pi^{*}\right)$ states of interest, since ISC driven by direct SOC does not explain the high triplet quantum yield in these systems. ${ }^{23}$ The derivatives of the SOMEs (OSOMEs) with respect to the mass-weighted normal coordinates were obtained by three-point finite differences technique. ${ }^{39}$ Minaev et al. ${ }^{40}$ have previously derived the vibronic SOC integrals by making use of a very elegant first and second order response theory formalism as implemented in the DALTON program. This involves a Herzberg-Teller expansion of the transition dipole moment of a spin-forbidden transition as a whole.

In this paper, a recent implementation of a time-dependent approach to vibronic spin-orbit coupling was applied for calculating the ISC rates $\left(k_{\mathrm{ISC}}\right){ }^{41,42}$ In this method, $k_{\mathrm{ISC}}$ is calculated as the integral of the time correlation function. ${ }^{41,42}$ This approach has been extended to cover also the finitetemperature regime by assuming a Boltzmann distribution of initial vibronic states. ${ }^{43}$ The dependence of $k_{\text {ISC }}$ on technical parameters is presented as ESI. $\dagger$

\section{Results and discussion}

First, we present a brief description of low-lying electronic states of oxonine and selenine. The computed data is compared 
with the reported measurements in aqueous solution by using solvation models. A detailed discussion of the photophysics of thionine can be found in our previous work. ${ }^{22,23}$ Some results already reported for thionine are shown here for the sake of the discussion. Thereafter, the consequences of replacing the sulphur atom by oxygen and selenium on the photophysics are discussed.

\subsection{Vertical spectra}

The DFT/MRCI vertical excitation energies of the low-lying singlet and triplet states of oxonine and selenine together with their leading electronic configurations at the ground-state geometry are presented in Table 1 . Selected geometrical parameters of the ground state minima are presented in the ESI $\dagger$ (Fig. S2). In addition the low-lying valence molecular orbitals (MOs), which dominate the corresponding low-lying excitations of selenine, are depicted in Fig. 2. The MOs for oxonine are similar to those of selenine and are depicted in the ESI $\dagger$ (Fig. S4). They mainly differ in the electron densities of the $\pi_{\mathrm{H}-1}, \mathrm{n}_{\mathrm{H}-4}$ and $\pi_{\mathrm{L}}^{*}$ MOs at the oxygen atom.

In vacuum, the electronic ground state minima of oxonine and selenine are $C_{2 \mathrm{v}}$ symmetric, in analogy to thionine. The geometrical variations may be found in the ESI $\dagger$ (Fig. S2). In the Franck-Condon (FC) region, the vertical ordering of the lowest singlet and triplet states of oxonine and selenine remains the same as in thionine (see Table 1). The characters of the states of interest are also the same in the three dyes: the $S_{1}$ and $T_{1}$ states have $\pi_{\mathrm{H}} \pi_{\mathrm{L}}{ }^{*}$ character, the $\mathrm{S}_{2}$ and $\mathrm{T}_{2}$ states are dominated by a $\pi_{\mathrm{H}-1} \pi_{\mathrm{L}}{ }^{*}$ configuration and, the $\mathrm{S}_{3}$ and $\mathrm{T}_{3}$ states are characterized by a $\mathrm{n}_{\mathrm{H}-4} \pi_{\mathrm{L}}^{*}$ transition.

The energetic position of the $T_{1}\left(\pi_{\mathrm{H}} \pi_{\mathrm{L}}{ }^{*}\right)$ state is remarkably constant in all cases. The $\mathrm{S}_{1}\left(\pi_{\mathrm{H}} \pi_{\mathrm{L}}{ }^{*}\right)$ state is found to be the optically bright state in the three dyes with oscillator strengths $>0.8$. Despite the somewhat different structures of the central rings which are due to the size of the heteroatom of this series $(\mathrm{X}=\mathrm{O}, \mathrm{S}, \mathrm{Se})$, the absorption spectra in all the cases are quite similar and the $\mathrm{S}_{1}$ state absorption is in the energy range of 2.39$2.26 \mathrm{eV}$ (Table 1). The excitation energy of the $\mathrm{S}_{1}\left(\pi_{\mathrm{H}} \pi_{\mathrm{L}}{ }^{*}\right)$ state of oxonine is $0.1 \mathrm{eV}$ higher than in thionine, whereas the $\mathrm{T}_{1}\left(\pi_{\mathrm{H}} \pi_{\mathrm{L}}{ }^{*}\right)$ state is nearly unaffected by hetero-substitution $(\approx 0.02 \mathrm{eV})$.

Due to the compact electron density of the oxygen p-orbitals, as compared to selenium, the exchange interaction is much

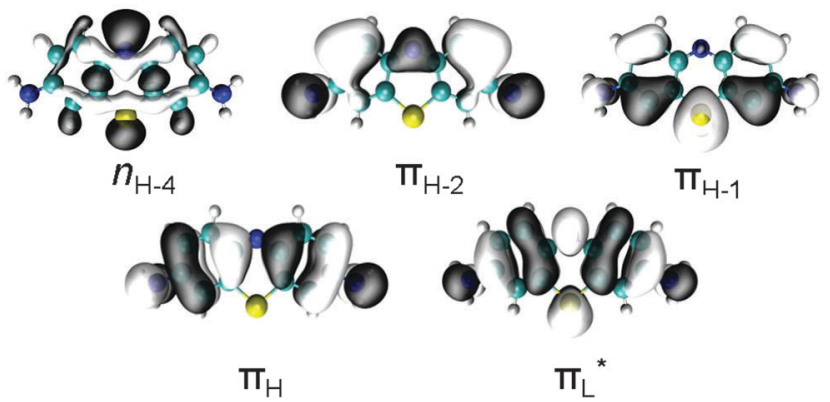

Fig. 2 Frontier Kohn-Sham molecular orbitals computed at the ground state minimum of selenine (isovalue 0.02).

larger in oxonine. This is reflected in the larger singlet-triplet energy gap in the vertical excitation spectrum of oxonine. In oxonine only one triplet state $\left(\mathrm{T}_{1}\left(\pi_{\mathrm{H}} \pi_{\mathrm{L}}{ }^{*}\right)\right)$ is below the $\mathrm{S}_{1}$ state in the vertical spectrum at the ground state geometry, whereas two triplet states $\left(\mathrm{T}_{1}\left(\pi_{\mathrm{H}} \pi_{\mathrm{L}}{ }^{*}\right)\right.$ and $\left.\mathrm{T}_{2}\left(\pi_{\mathrm{H}-1} \pi_{\mathrm{L}}{ }^{*}\right)\right)$ are found below this state in thionine and selenine.

Electrostatic interaction and hydrogen bonding with water through models $\mathrm{OXH}^{+} 3 \mathrm{Wa}$ and $\mathrm{SEH}^{+} 3 \mathrm{Wa}$ (Fig. 3) affects the energetical layout of the electronic states. Vertical energies are displayed in Table 1 . As expected, the $\pi \pi^{*}$ states are red-shifted, whereas the $n \pi^{*}$ states are blue-shifted due to hydration. The red shifts experienced by the various $\pi_{\mathrm{H}} \pi_{\mathrm{L}}{ }^{*}$ states are larger (around $\delta_{\mathrm{w}}=-0.12$ to $-0.21 \mathrm{eV}$ ) than the solvent shifts obtained for the $\pi_{\mathrm{H}-1} \pi_{\mathrm{L}}{ }^{*}$ states $\left(\delta_{\mathrm{w}}=-0.03\right.$ to $\left.-0.07 \mathrm{eV}\right)$. These results show that the heavy atom effect in the absorption spectrum of the three dyes is very small which is very favourable for the potential applicability of these dyes. This behaviour of the $\pi \pi^{*}$ excited states has been also observed experimentally in aqueous solution. ${ }^{17,18,45}$

The calculated DFT/MRCI electronic excitation energy of $\Delta E_{\mathrm{W}}=2.25 \mathrm{eV}$ for the bright $\mathrm{S}_{1}\left(\pi_{\mathrm{H}} \pi_{\mathrm{L}}{ }^{*}\right)$ state of oxonine agrees well with the reported experimental absorption maximum of $2.14 \mathrm{eV}$ in aqueous solution. ${ }^{18}$ For selenine a value of $\Delta E_{\mathrm{w}}=$ $2.02 \mathrm{eV}$ determined in reverse microemulsions of benzene/ acetyl-dimethylbenzylammonium chloride in $\mathrm{H}_{2} \mathrm{O}^{45}$ is the only available for comparison and agrees well with our calculated value of $2.14 \mathrm{eV}$ in aqueous solution. In contrast, no experimental data are available for the spectroscopically dark $n \pi^{*}$ states.

Table $1 \mathrm{DFT} / \mathrm{MRCl}$ vertical excitation energies (eV) in vacuum $\left(\Delta E_{\mathrm{vac}}\right)$ and aqueous solution $\left(\Delta E_{\mathrm{w}}\right)$ using solvation with COSMO and micro-hydration with three explicit water molecules $\left(\mathrm{OXH}^{+} 3 \mathrm{Wa}\right.$ and $\mathrm{SEH}^{+} 3 \mathrm{Wa}$ models). The absorption oscillator strengths $f(r)$ are shown in parentheses

\begin{tabular}{|c|c|c|c|c|c|c|c|}
\hline Electronic state & Character & \multicolumn{2}{|l|}{ Oxonine $^{a}$} & \multicolumn{2}{|l|}{ Thionine $^{b, c}$} & \multicolumn{2}{|l|}{ Selenine $^{b}$} \\
\hline $\mathrm{S}_{1}\left(1^{1} \mathrm{~B}_{1}\right)$ & $\pi_{\mathrm{H}} \pi_{\mathrm{L}}^{*}$ & $2.39(0.998)$ & $2.25^{d}(1.026)$ & $2.29(0.833)$ & $2.17^{e}(0.875)$ & $2.26(0.818)$ & $2.14^{f}(0.858)$ \\
\hline $\mathrm{S}_{3}\left(1^{1} \mathrm{~B}_{2}\right)$ & $\mathrm{n}_{\mathrm{H}-4} \pi_{\mathrm{L}}^{*}$ & $3.16(0.003)$ & $3.60(0.002)$ & $3.11(0.003)$ & $3.52(0.003)$ & $3.01(0.003)$ & $3.50(0.003)$ \\
\hline $\mathrm{T}_{1}\left(1^{3} \mathrm{~B}_{1}\right)$ & $\pi_{\mathrm{H}} \pi_{\mathrm{L}}^{*}$ & 1.61 & 1.40 & 1.63 & 1.46 & 1.61 & 1.43 \\
\hline$T_{2}\left(1^{3} A_{1}\right)$ & $\pi_{\mathrm{H}-1} \pi_{\mathrm{L}}^{*}$ & 2.49 & 2.46 & 2.11 & 2.07 & 1.97 & 1.92 \\
\hline $\mathrm{T}_{3}\left(1^{3} \mathrm{~B}_{2}\right)$ & $\mathrm{n}_{\mathrm{H}-4} \pi_{\mathrm{L}}^{*}$ & 2.80 & 3.30 & 2.78 & 3.23 & 2.69 & 3.22 \\
\hline
\end{tabular}

${ }^{a} \mathrm{DFT} / \mathrm{MRCI} / \mathrm{SV}(\mathrm{P}) .{ }^{b} \mathrm{DFT} / \mathrm{MRCI} / \mathrm{TZVP} .{ }^{c}$ Ref. $22 .{ }^{d} 2.14 \mathrm{eV}$ for oxonine in aqueous solution. ${ }^{18} e{ }^{e} 2.08 \mathrm{eV}$ for thionine in aqueous solution. ${ }^{44} f$ 2.02 eV for selenine in benzene/cetyldimethylbenzylammonium chloride/ $\mathrm{H}_{2} \mathrm{O}$ reverse microemulsions. ${ }^{45}$ 


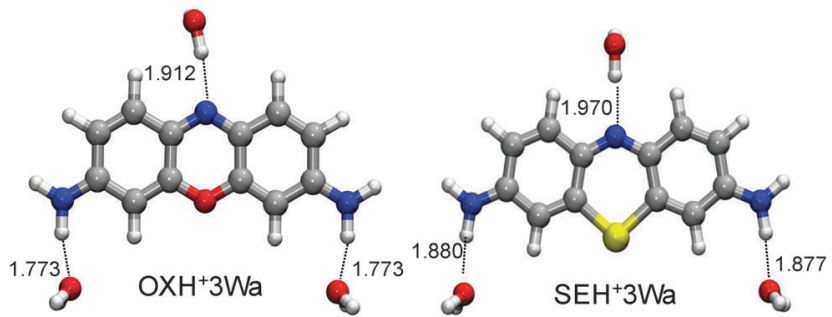

Fig. 3 Ground state hydration models for selenine $\left(\mathrm{SEH}^{+} 3 \mathrm{Wa}\right)$ and oxonine $\left(\mathrm{OXH}^{+} 3 \mathrm{Wa}\right)$.

\subsection{Excited state minima and adiabatic excitation energies}

The relative adiabatic energies of the low-lying singlet and triplet states reveal the accessible photophysical pathways for the dissipation of the excess energy of the dyes. In the following, we analyze the adiabatic excitation energies calculated at the computed $\pi \pi^{*}$ excited state geometries of oxonine and selenine (see Table 2).

3.2.1 Vacuum. The computed $\mathrm{S}_{1} / \mathrm{T}_{1}\left(\pi_{\mathrm{H}} \pi_{\mathrm{L}}{ }^{*}\right)$ and $\mathrm{S}_{2} / \mathrm{T}_{2}\left(\pi_{\mathrm{H}-1} \pi_{\mathrm{L}}{ }^{*}\right)$ excited state geometries of selenine were found to be minima at the TD-B3LYP/TZVP level (Fig. S1 in ESI $\dagger$ ). In the case of oxonine, however, only the $\mathrm{T}_{1}\left(\pi_{\mathrm{H}} \pi_{\mathrm{L}}{ }^{*}\right)$ and $\mathrm{T}_{2}\left(\pi_{\mathrm{H}-1} \pi_{\mathrm{L}}{ }^{*}\right)$ nuclear arrangements are minima on the TD-B3LYP/SV(P) PES (Fig. S2 in ESI $\dagger$ ). The optimized $C_{2 \mathrm{v}}$ structures of the $\mathrm{S}_{1}\left(\pi_{\mathrm{H}} \pi_{\mathrm{L}}{ }^{*}\right)$ and $\mathrm{S}_{2}\left(\pi_{\mathrm{H}-1} \pi_{\mathrm{L}}{ }^{*}\right)$ states of oxonine turn out to be first order saddle points at the TD-B3LYP/ SV(P) level, with imaginary frequencies of $i 2475 \mathrm{~cm}^{-1}$ and $i 1342$ $\mathrm{cm}^{-1}$ ( $B_{1}$-symmetric modes), respectively. Their corresponding Hessians (which were determined by finite differences) are asymmetric with large differences between $H_{i j}$ and $H_{j i}$ matrix elements. We calculated the TD-DFT and DFT/MRCI energies along the imaginary mode and found that the TD-DFT PES exhibits a shallow double minimum potential well caused by a $S_{1}-S_{2}$ conical intersection located extremely close to this geometry (see Fig. S1, ESI $\dagger$ ). We verified that there is neither root flipping nor considerable state mixing in the numerical frequency calculation due to this nearby crossing. The $C_{2 \mathrm{v}}$-symmetric $\mathrm{S}_{1}\left(\pi_{\mathrm{H}} \rightarrow \pi_{\mathrm{L}}{ }^{*}\right)$ and $\mathrm{S}_{2}\left(\pi_{\mathrm{H}-1} \rightarrow\right.$ $\left.\pi_{\mathrm{L}}^{*}\right)$ stationary points were found to correspond to minima on the DFT/MRCI PESs. Hence, we used both stationary points with $C_{2 \mathrm{v}}$

Table 2 Adiabatic DFT/MRCl excitation energies (eV) in vacuum ( $\left.\Delta E_{\mathrm{vac}}^{\mathrm{ad}}\right)$ and in aqueous solution ( $\left.\Delta E_{\mathrm{w}}^{\mathrm{ad}}\right)$

\begin{tabular}{|c|c|c|c|c|c|c|}
\hline \multirow[b]{2}{*}{ State } & \multicolumn{2}{|c|}{ Oxonine $^{a}$} & \multicolumn{2}{|c|}{ Thionine $^{b, c}$} & \multicolumn{2}{|c|}{ Selenine $^{b}$} \\
\hline & $\Delta E_{\mathrm{vac}}^{\mathrm{ad}}$ & $\Delta E_{\mathrm{w}}^{\mathrm{ad}}$ & $\Delta E_{\mathrm{vac}}^{\mathrm{ad}}$ & $\Delta E_{\mathrm{w}}^{\mathrm{ad}}$ & $\Delta E_{\mathrm{vac}}^{\mathrm{ad}}$ & $\Delta E_{\mathrm{w}}^{\mathrm{ad}}$ \\
\hline \multirow[t]{2}{*}{$\mathrm{S}_{1}$} & \multicolumn{2}{|c|}{$\pi_{\mathrm{H}} \pi_{\mathrm{L}}^{*}(81 \%)^{d}$} & \multicolumn{2}{|c|}{$\pi_{\mathrm{H}} \pi_{\mathrm{L}}^{*}(80 \%)^{d}$} & \multicolumn{2}{|c|}{$\pi_{\mathrm{H}} \pi_{\mathrm{L}}^{*}(80 \%)^{d}$} \\
\hline & 2.35 & 2.21 & 2.27 & 2.14 & 2.24 & 2.12 \\
\hline \multirow[t]{2}{*}{$\mathrm{S}_{2}$} & \multicolumn{2}{|c|}{$\pi_{\mathrm{H}-1} \pi_{\mathrm{L}}^{*}(81 \%)$} & \multicolumn{2}{|c|}{$\begin{array}{l}\pi_{\mathrm{H}-1} \pi_{\mathrm{L}}^{*}(45 \%) \\
\pi_{\mathrm{H}} \pi_{\mathrm{L}}^{*}(36 \%)\end{array}$} & \multicolumn{2}{|c|}{$\pi_{\mathrm{H}-1} \pi_{\mathrm{L}}^{*}(82 \%)$} \\
\hline & 2.62 & 2.57 & 2.29 & 2.23 & 2.20 & 2.13 \\
\hline \multirow[t]{2}{*}{$\mathrm{T}_{1}$} & \multicolumn{2}{|c|}{$\pi_{\mathrm{H}} \pi_{\mathrm{L}}^{*}(92 \%)$} & \multicolumn{2}{|c|}{$\pi_{\mathrm{H}} \pi_{\mathrm{L}}^{*}(92 \%)$} & \multicolumn{2}{|c|}{$\pi_{\mathrm{H}} \pi_{\mathrm{L}}^{*}(92 \%)$} \\
\hline & 1.61 & 1.40 & 1.63 & 1.46 & 1.62 & 1.44 \\
\hline \multirow[t]{2}{*}{$\mathrm{T}_{2}$} & \multicolumn{2}{|c|}{$\pi_{\mathrm{H}-1} \pi_{\mathrm{L}}{ }^{*}(87 \%)$} & \multicolumn{2}{|c|}{$\pi_{\mathrm{H}} \pi_{\mathrm{L}}^{*}(88 \%)$} & \multicolumn{2}{|c|}{$\pi_{\mathrm{H}} \pi_{\mathrm{L}}^{*}(88 \%)$} \\
\hline & 2.33 & 2.30 & 1.97 & 1.93 & 1.85 & 1.80 \\
\hline
\end{tabular}

${ }^{a}$ DFT/MRCI/SV(P). ${ }^{b}$ DFT/MRCI/TZVP. ${ }^{c}$ Ref. $23 .{ }^{d}$ Percentage of the dominant contributions in parenthesis. symmetry for these two singlet states in oxonine for further discussion.

Structural relaxation has minor impact on the energy of the $\mathrm{S}_{1}\left(\pi_{\mathrm{H}} \pi_{\mathrm{L}}{ }^{*}\right)$ electronic state of oxonine and selenine (2.35 and $2.24 \mathrm{eV})$. The effect is more pronounced for the $S_{2}\left(\pi_{\mathrm{H}-1} \pi_{\mathrm{L}}{ }^{*}\right)$ state. As the energy gap between the $\mathrm{S}_{1}\left(\pi_{\mathrm{H}} \pi_{\mathrm{L}}{ }^{*}\right)$ and $\mathrm{S}_{2}\left(\pi_{\mathrm{H}-1} \pi_{\mathrm{L}}{ }^{*}\right)$ states decreases along the series from $X=O$ to $X=$ Se (see Table 2), a reversal of the state ordering is observed in the case of selenine. Adiabatically, the $\mathrm{S}_{2}\left(\pi_{\mathrm{H}-1} \pi_{\mathrm{L}}{ }^{*}\right)$ state of selenine is located slightly below the $S_{1}\left(\pi_{\mathrm{H}} \pi_{\mathrm{L}}{ }^{*}\right)$ state in vacuum. At the geometry of the $S_{1}\left(\pi_{\mathrm{H}} \pi_{\mathrm{L}}{ }^{*}\right)$ state minima of the three dyes, only triplet $\left(\pi \pi^{*}\right)$ states are energetically below $S_{1}\left(\pi_{H^{\prime}} \pi_{L}^{*}\right)$ state. On the other hand, all the $S_{3}\left(n \pi^{*}\right)$ states are energetically located above this state: $3.31 \mathrm{eV}$ for oxonine, $3.26 \mathrm{eV}$ for thionine $\mathrm{e}^{23}$ and $3.16 \mathrm{eV}$ for selenine. At the geometry of the $\mathrm{S}_{2}\left(\pi_{\mathrm{H}-1} \pi_{\mathrm{L}}{ }^{*}\right)$ state of selenine this situation does not change where the $S_{3}\left(n \pi^{*}\right)$ state shows up at $3.13 \mathrm{eV}$. These states will not be populated via IC after excitation to the bright $S_{1}\left(\pi_{H} \pi_{L}^{*}\right)$ states. Nevertheless, the $\mathrm{S}_{3}\left(\mathrm{n} \pi^{*}\right)$ states contribute to the vibronic coupling between singlet and triplet states (see Section 3.3).

There is almost no energetic relaxation of the $\mathrm{T}_{1}\left(\pi_{\mathrm{H}} \pi_{\mathrm{L}}{ }^{*}\right)$ state of the dyes. The energy of the $\mathrm{T}_{2}\left(\pi_{\mathrm{H}-1} \pi_{\mathrm{L}}{ }^{*}\right)$ state shows more pronounced stabilization upon geometry relaxation $(\leq 0.16 \mathrm{eV})$. This different trend causes the adiabatic $S_{1}-T_{1}\left(\pi_{\mathrm{H}} \pi_{\mathrm{L}}^{*}\right)$ energy gap to decrease slightly in the series. In contrast, the $S_{1}\left(\pi_{\mathrm{H}} \pi_{\mathrm{L}}{ }^{*}\right)$ and $\mathrm{T}_{2}\left(\pi_{\mathrm{H}-1} \pi_{\mathrm{L}}{ }^{*}\right)$ states become energetically more separated from oxonine to selenine than in the FC region.

3.2.2 Aqueous solution. Estimates of the adiabatic excitation energies of the low-lying energy $\pi \pi^{*}$ states determined in aqueous environment $\left(\Delta E_{\mathrm{w}}^{\mathrm{ad}}\right)$ are also presented in Table 2 . Due to the large blue shifts of the $n \pi^{*}$ states experienced in aqueous solution, these are not relevant for the photophysical processes investigated here and have been excluded from this discussion.

Considering experimental measurements, the fluorescence spectrum of oxonine (and thionine) ${ }^{22}$ in aqueous solution is available for comparison. The estimated adiabatic energy of the $\mathrm{S}_{1}\left(\pi_{\mathrm{H}} \pi_{\mathrm{L}}{ }^{*}\right)$ state of oxonine $(2.21 \mathrm{eV})$ agrees quite well with the experimental value of $2.11 \mathrm{eV}$ estimated from the onset of the fluorescence emission band in acidic aqueous solution. ${ }^{46}$

Upon solvation, the adiabatic energy gaps between the $\mathrm{S}_{1}\left(\pi_{\mathrm{H}} \pi_{\mathrm{L}}{ }^{*}\right)$ and the $\mathrm{T}_{1}\left(\pi_{\mathrm{H}} \pi_{\mathrm{L}}{ }^{*}\right)$ and $\mathrm{T}_{2}\left(\pi_{\mathrm{H}} \pi_{\mathrm{L}}{ }^{*}\right)$ states change by less than $\sim 0.1 \mathrm{eV}$ in all the cases as compared to vacuum (see Table 2). These small shifts suggest that the energy distribution of the singlet and triplet sates is basically the same as in vacuum. However, a closer look at Table 2 tells a different story. In oxonine there are two triplet states $\left(\mathrm{T}_{1}\right.$ and $\left.\mathrm{T}_{2}\right)$ energetically available from the $S_{1}$ state in vacuum, whereas in water there is only one, namely, the $T_{1}$ state, the $T_{2}$ state being located $0.09 \mathrm{eV}$ above the $\mathrm{S}_{1}$ state. In thionine, the $\mathrm{T}_{1}$ and $\mathrm{T}_{2}$ states are clearly below the bright $\mathrm{S}_{1}$ state in aqueous solution, while the $S_{2}$ state is located substantially above the $\mathrm{S}_{1}$ state. The first two singlet excited states of selenine are adiabatically degenerate in water. Therefore, transitions arising from the $S_{1}\left(\pi_{\mathrm{H}} \pi_{\mathrm{L}}{ }^{*}\right)$ and $\mathrm{S}_{2}\left(\pi_{\mathrm{H}-1} \pi_{\mathrm{L}}{ }^{*}\right)$ states of selenine may all participate in the photophysics in both vacuum and aqueous solution. 


\subsection{Photophysics: radiative $v s$. radiationless channels}

For an efficient ISC, three prerequisites have to be fulfilled: (i) there should be a considerable overlap of the vibrational wavefunctions of the involved singlet and triplet states, (ii) SOC should be reasonably strong and (iii) the density of vibrational levels in the accepting state should be high at the energy of the initial state. According to the El-Sayed rule, ISC is very efficient if the transition involves a change of molecular orbital character: the rate of ISC involving $\left(\pi \pi^{*}\right)$ and $\left(\mathrm{n} \pi^{*}\right)$ states should, thus, be much larger than that between two $\left(\pi \pi^{*}\right)$ or two $\left(n \pi^{*}\right)$ states. Nevertheless, the processes involving states with similar MO character, e.g., ${ }^{1}\left(\pi \pi^{*}\right) \rightsquigarrow{ }^{3}\left(\pi \pi^{*}\right)$ ISC, may gain intensity when a Herzberg-Teller type expansion of the spin-orbit coupling (vibronic spin-orbit coupling) is taken account of. Such a coupling is driven via promoting modes. The promoting mode is responsible for the vibronic perturbation and is generally a nontotally symmetric mode. In the present case of $\left(\pi \pi^{*}\right)-\left(\pi \pi^{*}\right)$ coupling, out-of-plane ( $B_{2}$ - and $A_{2}$-symmetric) modes may act as

Table 3 Spin-orbit coupling matrix elements (SOMEs, $i \mathrm{~cm}^{-1}$ ) between low-lying singlet and triplet states at the corresponding adiabatic minimum geometry of the $S_{1}\left(\pi_{\mathrm{H}} \pi_{\mathrm{L}}{ }^{*}\right)$ and $\mathrm{S}_{2}\left(\pi_{\mathrm{H}-1} \pi_{\mathrm{L}}{ }^{*}\right)$ states in vacuum

\begin{tabular}{|c|c|c|c|c|}
\hline \multirow[b]{2}{*}{ SOMEs } & \multirow{2}{*}{$\frac{\text { Oxonine }}{\text { @ } S_{1}}$} & \multirow{2}{*}{$\frac{\text { Thionine }^{a}}{\text { a }_{1}}$} & \multicolumn{2}{|c|}{ Selenine } \\
\hline & & & @ $S_{1}$ & (a) $\mathrm{S}_{2}$ \\
\hline $\begin{array}{l}\left.\mathrm{S}_{1}\left|\hat{H}_{\mathrm{SO}}\right| \mathrm{T}_{1}\right\rangle \\
\left\langle\mathrm{S}_{1}\left|\hat{H}_{\mathrm{SO}}\right| \mathrm{T}_{2(y)}\right\rangle \\
\left\langle\mathrm{S}_{1}\left|\hat{H}_{\mathrm{SO}}\right| \mathrm{T}_{3(z)}\right\rangle\end{array}$ & $\begin{array}{l}- \\
-0.01 \\
-0.61\end{array}$ & $\begin{array}{r}- \\
-0.08 \\
0.39\end{array}$ & $\begin{array}{l}- \\
-0.23 \\
-6.99\end{array}$ & $\begin{array}{l}0.19^{b} \\
-{ }^{c} \\
-43.41^{d}\end{array}$ \\
\hline
\end{tabular}

promoting modes. Accepting modes provide the FC factors and are either totally symmetric or occur in even quanta of nontotally symmetric modes. ${ }^{47}$

3.3.1 Photophysics in vacuum. The computed SOMEs between the $S_{1,2}\left(\pi \pi^{*}\right)$ and $T_{3}\left(n \pi^{*}\right)$ states are found to increase substantially in going from oxonine to selenine (Table 3). However, as has already been discussed in the previous sections, these direct ISC channels, namely $\left(\pi \pi^{*}\right) \rightsquigarrow\left(n \pi^{*}\right)$, are energetically not feasible in these dyes. However, as we have demonstrated earlier for thionine, ${ }^{23}$ ISC may be promoted by vibronic coupling between these states. Here, the $S\left(\pi \pi^{*}\right) \rightsquigarrow \rightarrow T\left(\pi \pi^{*}\right)$ transitions gain intensity through vibronic coupling with a nearby $\mathrm{n} \pi^{*}$ state, which indirectly causes the heavy-atom effect to become apparent in the photophysical kinetics.

The proximity of the $\mathrm{T}_{2}\left(\pi_{\mathrm{H}-1} \pi_{\mathrm{L}}{ }^{*}\right)$ and the $\mathrm{T}_{3}\left(\mathrm{n}_{\mathrm{H}-4} \pi_{\mathrm{L}}{ }^{*}\right)$ states and the larger concentration of the electron density at the $\mathrm{X}$ atom in the MOs involved in these electronic excitations (which increases direct SOC) facilitates the $S_{i} \leadsto T_{2}$ channels. This can be seen in the computed derivatives of the SOMEs with respect to the vibrational normal coordinates (OSOMEs) between the low-lying singlet and triplet states calculated at the $\mathrm{S}_{1}\left(\pi_{\mathrm{H}} \pi_{\mathrm{L}}^{*}\right)$ and $\mathrm{S}_{2}\left(\pi_{\mathrm{H}-1} \pi_{\mathrm{L}}^{*}\right)$ state minima, Table 4 .

As expected, the largest OSOMEs are found for selenine and nearly negligible values are found for oxonine. This means that in these dyes the heavy atom substitution $\mathrm{X}=\mathrm{O}$, $\mathrm{S}$, Se has substantial effects by increasing the vibronic SOC, as shown by the values of the OSOMEs. Nevertheless, one should bear in mind that, since Duschinsky rotations are included, all vibrational modes may act as accepting modes due to the rotations between initial and final state modes. Therefore, we have used

Table 4 Derivatives of the SOMEs (OSOMEs, $i \mathrm{~cm}^{-1}$ ) with respect to the corresponding (dimensionless) normal coordinates at the equilibrium geometry of the $S_{1}\left(\pi_{\mathrm{H}} \pi_{\llcorner}{ }^{*}\right)$ and $S_{2}\left(\pi_{\mathrm{H}-1} \pi_{\llcorner}{ }^{*}\right)$ excited states in vacuum

\begin{tabular}{|c|c|c|c|c|c|c|c|c|c|c|c|}
\hline \multicolumn{3}{|l|}{ Oxonine $^{a}$} & \multicolumn{3}{|c|}{ Thionine $^{b, c}$} & \multicolumn{6}{|l|}{ Selenine $^{b}$} \\
\hline $68.95\left(B_{2}\right)$ & 0.05 & 0.05 & $50.0\left(A_{2}\right)$ & 0.27 & 2.23 & $35.3\left(A_{2}\right)$ & 1.76 & 7.96 & $36.20\left(B_{2}\right)$ & 1.69 & 0.54 \\
\hline $184.21\left(A_{2}\right)$ & 0.02 & 0.21 & $127.2\left(A_{2}\right)$ & 0.18 & 1.00 & $138.1\left(A_{2}\right)$ & 0.89 & 2.49 & $147.55\left(A_{2}\right)$ & 1.17 & 0.64 \\
\hline $184.54\left(B_{2}\right)$ & 0.07 & 0.00 & $169.2\left(B_{2}\right)$ & 0.19 & 0.19 & $146.1\left(B_{2}\right)$ & 1.08 & 1.67 & $149.83\left(B_{2}\right)$ & 1.16 & 1.60 \\
\hline $283.90\left(B_{2}\right)$ & 0.03 & 0.00 & $170.3\left(A_{2}\right)$ & 0.05 & 0.12 & $174.7\left(B_{2}\right)$ & 0.66 & 1.31 & $178.23\left(B_{2}\right)$ & 1.08 & 0.77 \\
\hline $321.83\left(A_{2}\right)$ & 0.00 & 0.21 & $178.5\left(B_{2}\right)$ & 0.00 & 0.37 & $242.9\left(A_{2}\right)$ & 2.23 & 0.04 & $196.28\left(A_{2}\right)$ & 2.30 & 2.85 \\
\hline $449.70\left(A_{2}\right)$ & 0.03 & 0.13 & $397.9\left(B_{2}\right)$ & 0.06 & 0.33 & $400.9\left(B_{2}\right)$ & 1.27 & 0.30 & $315.16\left(B_{2}\right)$ & 8.81 & 1.02 \\
\hline $450.67\left(B_{2}\right)$ & 0.01 & 0.04 & $404.9\left(A_{2}\right)$ & 0.41 & 0.84 & $403.3\left(A_{2}\right)$ & 0.62 & 1.05 & $342.31\left(A_{2}\right)$ & 3.66 & 0.34 \\
\hline $463.46\left(B_{2}\right)$ & 0.04 & 0.08 & $477.2\left(A_{2}\right)$ & 0.01 & 0.14 & $405.8\left(B_{2}\right)$ & 0.59 & 1.06 & $393.61\left(B_{2}\right)$ & 4.37 & 1.16 \\
\hline $494.12\left(B_{2}\right)$ & 0.05 & 0.11 & $477.9\left(B_{2}\right)$ & 0.02 & 0.09 & $438.6\left(A_{2}\right)$ & 2.22 & 2.58 & $404.16\left(A_{2}\right)$ & 3.88 & 0.01 \\
\hline $497.84\left(A_{2}\right)$ & 0.01 & 0.08 & $527.0\left(B_{2}\right)$ & 0.08 & 1.00 & $471.2\left(B_{2}\right)$ & 1.76 & 6.91 & $434.84\left(A_{2}\right)$ & 6.39 & 1.93 \\
\hline $618.09\left(A_{2}\right)$ & 0.01 & 0.24 & $534.0\left(A_{2}\right)$ & 0.14 & 0.81 & $481.4\left(A_{2}\right)$ & 2.24 & 6.25 & $438.25\left(B_{2}\right)$ & 7.48 & 1.67 \\
\hline $872.96\left(B_{2}\right)$ & 0.02 & 0.12 & $826.4\left(A_{2}\right)$ & 0.05 & 0.44 & $826.2\left(A_{2}\right)$ & 0.32 & 1.42 & $833.08\left(A_{2}\right)$ & 3.96 & 0.99 \\
\hline $874.07\left(A_{2}\right)$ & 0.06 & 0.04 & $830.1\left(B_{2}\right)$ & 0.09 & 0.32 & $829.0\left(B_{2}\right)$ & 0.38 & 1.19 & $837.22\left(B_{2}\right)$ & 4.25 & 2.13 \\
\hline $995.20\left(A_{2}\right)$ & 0.02 & 0.07 & $947.7\left(A_{2}\right)$ & 0.03 & 0.41 & $947.5\left(A_{2}\right)$ & 0.68 & 1.86 & $926.52\left(A_{2}\right)$ & 1.52 & 0.24 \\
\hline $996.21\left(B_{2}\right)$ & 0.05 & 0.05 & $950.1\left(B_{2}\right)$ & 0.06 & 0.12 & $950.1\left(B_{2}\right)$ & 0.29 & 0.55 & $929.91\left(B_{2}\right)$ & 0.87 & 1.65 \\
\hline
\end{tabular}

${ }^{a}$ Results calculated at the DFT/MRCI/SV(P)//TD-B3LYP/SV(P). ${ }^{b}$ Results calculated at the DFT/MRCI/TZVP//TD-B3LYP/TZVP theoretical levels. ${ }^{c}$ Ref. 23. 
all vibrational modes as accepting modes in this work. In general, the magnitude of the OSOMEs between the $\mathrm{S}_{1}$ and $\mathrm{T}_{2}$ states is noticeably larger than the vibronic coupling with the $\mathrm{T}_{1}$ state for all chromophores. The calculated OSOMEs arising from the $\mathrm{S}_{2}\left(\pi_{\mathrm{H}-1} \pi_{\mathrm{L}}{ }^{*}\right)$ state of selenine show a stronger coupling with the $\mathrm{T}_{1}\left(\pi_{\mathrm{H}} \pi_{\mathrm{L}}{ }^{*}\right)$ state than with the $\mathrm{T}_{2}\left(\pi_{\mathrm{H}-1} \pi_{\mathrm{L}}{ }^{*}\right)$ state, a tendency which is expected due to symmetry criteria. The calculated OSOMEs promoted by the $B_{1}$-symmetric modes are approximately zero and were not included in Table 4 .

To understand the photophysical kinetics in the series $\mathrm{X}=\mathrm{O}$ to $\mathrm{X}=\mathrm{Se}$, the ISC and fluorescence rate constants are analyzed in the following. In order to be efficient, the ISC channels should be faster than the radiative decay. The calculated ISC rate constants $\left(k_{\mathrm{ISC}}\right)$ are listed in Table 5 . A detailed overview of the estimated rate constants using different technical parameters can be found in the ESI $\dagger$ (Tables S3-S5).

The nearly negligible OSOMEs for the coupling between the $S_{1}\left(\pi_{H} \pi_{L}^{*}\right)$ and $T_{1,2}\left(\pi \pi^{*}\right)$ states of oxonine (Table 4$)$ resulted in small rate constants: $k_{\text {ISC }}\left(\mathrm{S}_{1} \leadsto \mathrm{T}_{1}\right) \sim 10^{5}-10^{6} \mathrm{~s}^{-1}$ and $k_{\text {ISC }}\left(\mathrm{S}_{1} \leadsto \mathrm{T}_{2}\right) \sim 10^{7} \mathrm{~s}^{-1}$ (Table 5). For the latter channel, it is important to note that the adiabatic energies of the $S_{1}$ and $T_{2}$ states are nearly degenerate (Table 2 ). Therefore, the density of acceptor vibrational levels is extremely low and Fermi's golden rule (which is the basis of our approach) is not strictly applicable. This may happen even if the path connecting the minima of the potential energy surfaces exhibits a small barrier, i.e., if it is a thermally activated process. In this case, it is important to take into account the population of higher vibrational levels of the $S_{1}\left(\pi_{H} \pi_{L}^{*}\right)$ state at room temperature. For analysing this effect, we calculated a linearly interpolated energy profile connecting the minima of the $S_{1}\left(\pi_{\mathrm{H}} \pi_{\mathrm{L}}{ }^{*}\right)$ and $\mathrm{T}_{2}\left(\pi_{\mathrm{H}-1} \pi_{\mathrm{L}}{ }^{*}\right)$ states (see Fig. 4(a)) of oxonine. It is found that the energy difference between the adiabatic energy of the $S_{1}\left(\pi_{\mathrm{H}} \pi_{\mathrm{L}}{ }^{*}\right)$ state and the crossing point of the energy wells of the $S_{1}\left(\pi_{\mathrm{H}} \pi_{\mathrm{L}}{ }^{*}\right)$ and $\mathrm{T}_{2}\left(\pi_{\mathrm{H}-1} \pi_{\mathrm{L}}^{*}\right)$ states is approximately $175 \mathrm{~cm}^{-1}$ which is nearly $k_{\mathrm{B}} T$ at room temperature. As a consequence, the population transfer to the $T_{2}\left(\pi_{\mathrm{H}-1} \pi_{\mathrm{L}}{ }^{*}\right)$ state from the $S_{1}\left(\pi_{\mathrm{H}} \pi_{\mathrm{L}}{ }^{*}\right)$ is possible at ambient temperature at a rate of about $k_{\text {ISC }}\left(S_{1} \rightsquigarrow T_{2}\right) \sim$ $10^{7} \mathrm{~s}^{-1}$. This process may compete with the fluorescence decay with a $k_{\mathrm{F}}\left(\mathrm{S}_{0} \leftarrow \mathrm{S}_{1}\right)=2 \times 10^{8} \mathrm{~s}^{-1}$.
In thionine the $S_{1}\left(\pi_{\mathrm{H}} \pi_{\mathrm{L}}^{*}\right) \rightsquigarrow \mathrm{T}_{2}\left(\pi_{\mathrm{H}-1} \pi_{\mathrm{L}}^{*}\right)$ ISC was reported to proceed with a rate constant of $k_{\mathrm{ISC}} \approx 3 \times 10^{8} \mathrm{~s}^{-1}$, which was able to compete with the fluorescence from the $S_{1}\left(\pi_{\mathrm{H}} \pi_{\mathrm{L}}{ }^{*}\right)$ state $\left(k_{\mathrm{F}} \approx 2 \times 10^{8} \mathrm{~s}^{-1}\right)$ in vacuum. ${ }^{23}$ This $k_{\mathrm{ISC}}$ is at least one order of magnitude larger than that calculated for oxonine. The other energetically available ISC channels of thionine have rate constants which are two orders of magnitude smaller, hence, are not the dominating factors for the photophysics (Table 5).

As mentioned above, in selenine the $\mathrm{S}_{2}\left(\pi_{\mathrm{H}-1} \pi_{\mathrm{L}}^{*}\right)$ state is about $0.09 \mathrm{eV}$ (Table 1 ) above the optically bright $\mathrm{S}_{1}\left(\pi_{\mathrm{H}} \pi_{\mathrm{L}}{ }^{*}\right)$ state in the vertical absorption spectrum, whereas the adiabatic minimum of the $\mathrm{S}_{2}\left(\pi_{\mathrm{H}-1} \pi_{\mathrm{L}}{ }^{*}\right)$ state is about $0.04 \mathrm{eV}$ below that of the $S_{1}\left(\pi_{\mathrm{H}} \pi_{\mathrm{L}}^{*}\right)$ state (Table 2$)$. This opens another possibility, besides ISC, for the radiationless relaxation of the photoexcited bright $S_{1}\left(\pi_{H} \pi_{L}^{*}\right)$ state, namely, internal conversion (IC) to the $\mathrm{S}_{2}\left(\pi_{\mathrm{H}-1} \pi_{\mathrm{L}}^{*}\right)$ state. A linearly interpolated pathway between these states shows a conical intersection, whose energy is found to be isoenergetic with the $S_{1}$ minimum of selenine. This crossing point also appears to occur along the interpolated energy pathways connecting the minima of the $\mathrm{S}_{1}\left(\pi_{\mathrm{H}} \pi_{\mathrm{L}}{ }^{*}\right)-\mathrm{T}_{2}\left(\pi_{\mathrm{H}-1} \pi_{\mathrm{L}}{ }^{*}\right)$ and the $\mathrm{S}_{2}\left(\pi_{\mathrm{H}-1} \rightarrow \pi_{\mathrm{L}}^{*}\right)-\mathrm{T}_{1}\left(\pi_{\mathrm{H}} \rightarrow \pi_{\mathrm{L}}^{*}\right)$ states depicted in Fig. 4(b and c). This means that ISC channels starting from both singlet states are feasible (see Table 5).

Comparing the ISC rate constants arising from the $\mathrm{S}_{1}\left(\pi_{\mathrm{H}} \pi_{\mathrm{L}}{ }^{*}\right)$ state of selenine, the $S_{1}\left(\pi_{\mathrm{H}} \pi_{\mathrm{L}}{ }^{*}\right) \rightsquigarrow \mathrm{T}_{2}\left(\pi_{\mathrm{H}-1} \pi_{\mathrm{L}}{ }^{*}\right)$ channel is the dominant pathway $\left(k_{\mathrm{ISC}}=2 \times 10^{10} \mathrm{~s}^{-1}\right)$. After the $\mathrm{S}_{2}\left(\pi_{\mathrm{H}-1} \pi_{\mathrm{L}}{ }^{*}\right)$ state is populated by IC from the $S_{1}\left(\pi_{\mathrm{H}} \pi_{\mathrm{L}}{ }^{*}\right)$ state, it is expected that the $\mathrm{S}_{2}\left(\pi_{\mathrm{H}-1} \pi_{\mathrm{L}}{ }^{*}\right) \rightsquigarrow \mathrm{T}_{1}\left(\pi_{\mathrm{H}} \pi_{\mathrm{L}}^{*}\right)$ channel dominates the ISC $\left(k_{\text {ISC }}=1 \times 10^{10} \mathrm{~s}^{-1}\right)$. Moreover, these two ISC channels benefit from a crossing of the corresponding singlet and triplet state potential wells along linearly interpolated energy profiles connecting them (Fig. 4(b and c)), increasing the overlap between their vibrational wavefunctions. The crossing between the $\mathrm{T}_{1}\left(\pi_{\mathrm{H}} \pi_{\mathrm{L}}{ }^{*}\right)$ and $\mathrm{T}_{2}\left(\pi_{\mathrm{H}-1} \pi_{\mathrm{L}}{ }^{*}\right)$ potential wells observed in Fig. 4(c), and the parallel tracks of the $\mathrm{S}_{2}\left(\pi_{\mathrm{H}-1} \pi_{\mathrm{L}}{ }^{*}\right)$ and $\mathrm{T}_{2}\left(\pi_{\mathrm{H}-1} \pi_{\mathrm{L}}^{*}\right)$ states reflect the larger ISC rate constant found for the decay from the $S_{2}\left(\pi_{\mathrm{H}-1} \pi_{\mathrm{L}}{ }^{*}\right)$ state to the $\mathrm{T}_{1}\left(\pi_{\mathrm{H}} \pi_{\mathrm{L}}{ }^{*}\right)$ state as compared to the $\mathrm{T}_{2}\left(\pi_{\mathrm{H}-1} \pi_{\mathrm{L}}{ }^{*}\right)$ state.

All in all, the following photophysical kinetics is proposed to take place for selenine in vacuum: population transfer from the

Table 5 Calculated ISC rate constants $k_{\text {ISC }}\left[\mathrm{s}^{-1}\right]$ and adiabatic excitation energy differences $\Delta E^{\text {ad }}$ [eV] between the corresponding electronic states

\begin{tabular}{|c|c|c|c|c|c|c|}
\hline Channel & \multicolumn{2}{|c|}{ Oxonine $^{a}$} & \multicolumn{2}{|c|}{ Thionine $^{b}$} & \multicolumn{2}{|c|}{ Selenine ${ }^{b}$} \\
\hline \multicolumn{7}{|l|}{ Vacuum } \\
\hline $\mathrm{S}_{1}\left(\pi_{\mathrm{H}} \pi_{\mathrm{L}}^{*}\right) \rightsquigarrow \mathrm{T}_{2}\left(\pi_{\mathrm{H}-1} \pi_{\mathrm{L}}^{*}\right)$ & 0.02 & $10^{7 c}$ & 0.30 & $8 \times 10^{8}$ & 0.39 & $2 \times 10^{10}$ \\
\hline $\mathrm{S}_{2}\left(\pi_{\mathrm{H}-1} \pi_{\mathrm{L}}^{*}\right) \rightsquigarrow \mathrm{T}_{1}\left(\pi_{\mathrm{H}} \pi_{\mathrm{L}}{ }^{*}\right)$ & 1.01 & - & 0.66 & $\sim 10^{6 d}$ & 0.58 & $1 \times 10^{10}$ \\
\hline $\mathrm{S}_{2}\left(\pi_{\mathrm{H}-1} \pi_{\mathrm{L}}^{*}\right) \rightsquigarrow \mathrm{T}_{2}\left(\pi_{\mathrm{H}-1} \pi_{\mathrm{L}}^{*}\right)$ & 0.29 & - & 0.32 & $\sim 10^{6 d}$ & 0.35 & $1 \times 10^{9}$ \\
\hline $\mathrm{S}_{1}\left(\pi_{\mathrm{H}} \pi_{\mathrm{L}}{ }^{*}\right) \leadsto \mathrm{T}_{2}\left(\pi_{\mathrm{H}-1} \pi_{\mathrm{L}}{ }^{*}\right)$ & -0.09 & $10^{6 c}$ & 0.21 & $1 \times 10^{9}$ & 0.32 & $3 \times 10^{10}$ \\
\hline $\mathrm{S}_{2}\left(\pi_{\mathrm{H}-1} \pi_{\mathrm{L}}^{*}\right) \rightsquigarrow \mathrm{T}_{1}\left(\pi_{\mathrm{H}} \pi_{\mathrm{L}}^{*}\right)$ & 1.17 & - & 0.77 & - & 0.69 & $5 \times 10^{9}$ \\
\hline $\mathrm{S}_{2}\left(\pi_{\mathrm{H}-1} \pi_{\mathrm{L}}^{*}\right) \rightsquigarrow \mathrm{T}_{2}\left(\pi_{\mathrm{H}-1} \pi_{\mathrm{L}}^{*}\right)$ & 0.27 & - & 0.30 & - & 0.33 & $2 \times 10^{9}$ \\
\hline
\end{tabular}

All the ISC rate constants have been determined using a Gaussian damping function of width $10 \mathrm{~cm}^{-1}$. ${ }^{a}$ Results calculated at the DFT/MRCI/ $\mathrm{SV}(\mathrm{P}) / / \mathrm{TD}-\mathrm{B} 3 \mathrm{LYP} / \mathrm{SV}(\mathrm{P}) .{ }^{b}$ Results calculated at the DFT/MRCI/TZVP//TD-B3LYP/TZVP levels. ${ }^{c}$ Rate computed at $T=298 \mathrm{~K} .{ }^{d}$ Ref. 23. 

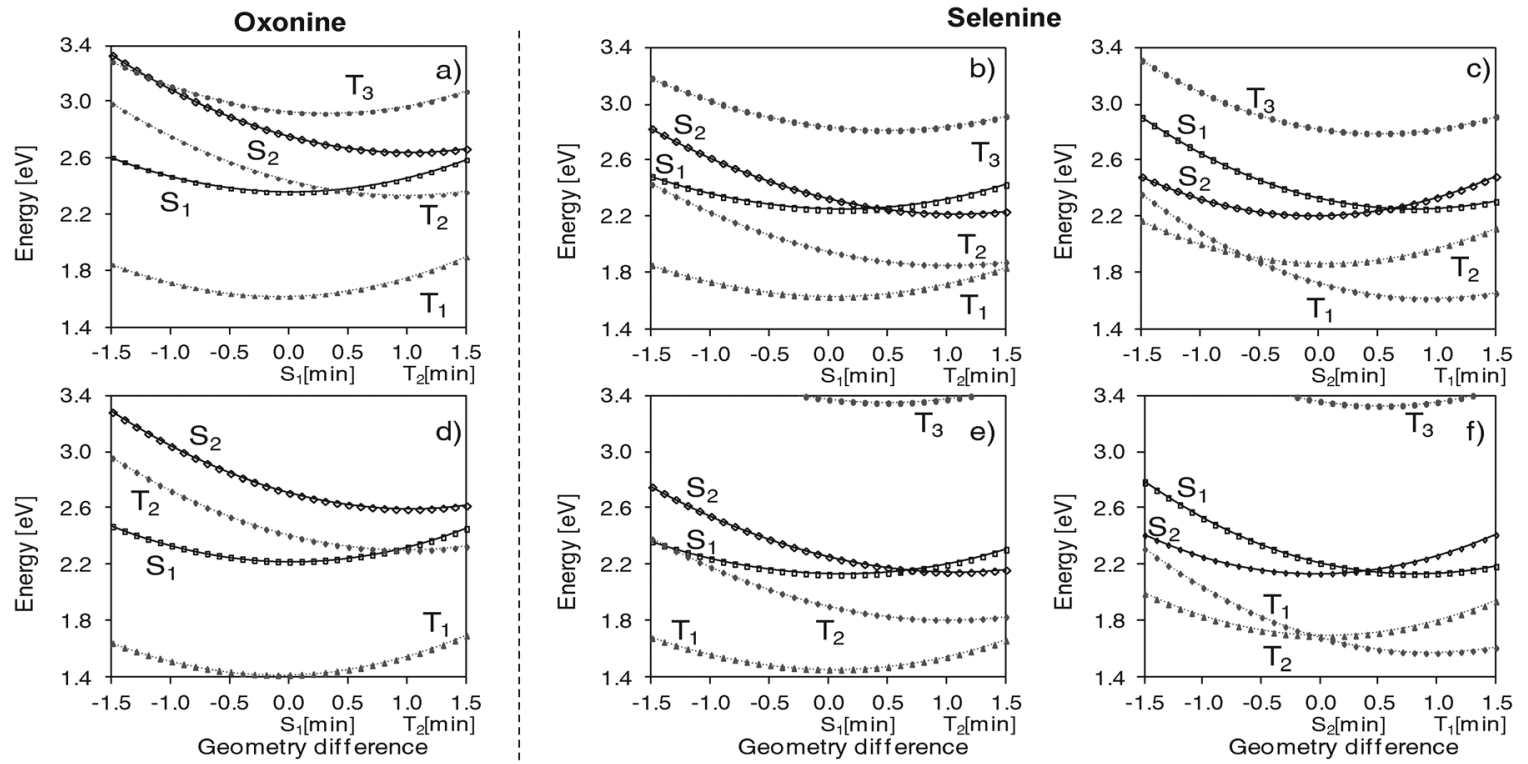

Fig. $4 \mathrm{DFT} / \mathrm{MRCl}$ energy profiles along a linearly interpolated path between the low-lying singlet and triplet state minima of oxonine and selenine in vacuum $(a-c)$ and in aqueous solution $(d-f)$.

$\mathrm{S}_{1}\left(\pi_{\mathrm{H}} \pi_{\mathrm{L}}^{*}\right)$ state may occur to the $\mathrm{S}_{2}\left(\pi_{\mathrm{H}-1} \pi_{\mathrm{L}}^{*}\right)$ state (by IC) and the $\mathrm{T}_{2}\left(\pi_{\mathrm{H}-1} \pi_{\mathrm{L}}^{*}\right)$ state (by ISC). The latter is followed by IC to the $\mathrm{T}_{1}\left(\pi_{\mathrm{H}} \pi_{\mathrm{L}}^{*}\right)$ state. The $\mathrm{S}_{2}\left(\pi_{\mathrm{H}-1} \pi_{\mathrm{L}}{ }^{*}\right)$ state depopulates directly to the lowest lying triplet state. The fluorescence decay from the $\mathrm{S}_{1}\left(\pi_{\mathrm{H}} \pi_{\mathrm{L}}^{*}\right)$ state is computed to have a rate constant of $k_{\mathrm{F}}=2 \times 10^{8} \mathrm{~s}^{-1}$, and is effectively quenched by ISC and IC radiationless processes. Thus, of the three dyes discussed in this section, we found selenine to be the most efficient triplet photosensitizer in vacuum, the triplet formation occurring faster by about three and two orders of magnitude as compared to oxonine and thionine analogues.

3.3.2 Photophysics in aqueous solution. As mentioned in Section 3.2.3, the photophysical kinetics is affected in different ways by hydration. Due to the fact that the $\mathrm{T}_{3}\left(\mathrm{n}_{\mathrm{H}-4} \pi_{\mathrm{L}}{ }^{*}\right)$ state experiences a large blue shift in aqueous solution (Table 1), the vibronic coupling and the ISC rates arising herefrom are expected to decrease. However, in our previous study we found that for thionine a small decrease in the energy gap between the $\mathrm{S}_{1}\left(\pi_{\mathrm{H}} \pi_{\mathrm{L}}{ }^{*}\right)$ and $\mathrm{T}_{2}\left(\pi_{\mathrm{H}-1} \pi_{\mathrm{L}}{ }^{*}\right)$ states leads to a substantial increase in the associated rate constant. ${ }^{23}$

In oxonine, the energy differences between the $\mathrm{S}_{1}\left(\pi_{\mathrm{H}} \pi_{\mathrm{L}}{ }^{*}\right)$ and $\mathrm{T}_{1,2}\left(\pi \pi^{*}\right)$ states are increased when the hydration shifts are applied to the adiabatic energies in vacuum (see Table 2). The ISC rate constant for the $S_{1}\left(\pi_{\mathrm{H}} \pi_{\mathrm{L}}^{*}\right) \rightsquigarrow \mathrm{T}_{1}\left(\pi_{\mathrm{H}} \pi_{\mathrm{L}}^{*}\right)$ channel in water is computed to be $k_{\mathrm{ISC}} \sim 10^{5}-10^{6} \mathrm{~s}^{-1}$, which is comparable to the isolated dye (Table 5). The $\mathrm{T}_{2}\left(\pi_{\mathrm{H}-1} \pi_{\mathrm{L}}{ }^{*}\right)$ state is no longer accessible from the minimum of the $\mathrm{S}_{1}\left(\pi_{\mathrm{H}} \pi_{\mathrm{L}}{ }^{*}\right)$ state $(\sim 0.1 \mathrm{eV})$ at low temperatures. This also causes the energy of the crossing point between the potential wells of these states to increase, as can be seen along the energy profiles calculated taking into account the corresponding hydration shifts (Fig. 4(d)). Thus, according to our calculations the deactivation via the $\mathrm{S}_{1}\left(\pi_{\mathrm{H}} \pi_{\mathrm{L}}{ }^{*}\right) \rightsquigarrow \mathrm{T}_{2}\left(\pi_{\mathrm{H}-1} \pi_{\mathrm{L}}{ }^{*}\right)$ channel is a thermally activated process for oxonine in water $\left(k_{\mathrm{ISC}} \sim 5 \times 10^{6} \mathrm{~s}^{-1}\right)$. These findings corroborate the observation that oxonine is a very efficient fluorophore (calculated $k_{\mathrm{F}}=2 \times 10^{8} \mathrm{~s}^{-1}$ ) in aqueous solution $\left(\phi_{\mathrm{F}}=1.00\right){ }^{18}$

As expected, the $\mathrm{S}_{1}\left(\pi_{\mathrm{H}} \pi_{\mathrm{L}}^{*}\right) \rightsquigarrow \mathrm{T}_{1}\left(\pi_{\mathrm{H}} \pi_{\mathrm{L}}^{*}\right)$ ISC rate constants of thionine $\left(k_{\mathrm{ISC}} \sim 10^{6} \mathrm{~s}^{-1}\right)$ and selenine $\left(k_{\mathrm{ISC}} \sim 10^{7} \mathrm{~s}^{-1}\right)$ are very similar to those calculated in vacuum (Table 5 ). In contrast, the ISC rate constant for the $\mathrm{S}_{1}\left(\pi_{\mathrm{H}} \pi_{\mathrm{L}}{ }^{*}\right) \rightsquigarrow \mathrm{T}_{2}\left(\pi_{\mathrm{H}-1} \pi_{\mathrm{L}}{ }^{*}\right)$ channel for thionine upon solvation increases to $k_{\mathrm{ISC}} \sim 10^{9} \mathrm{~s}^{-1}$ (Table 5) and is an order of magnitude faster than fluorescence $\left(k_{\mathrm{F}} \sim 10^{8} \mathrm{~s}^{-1}\right)$ which can be explained by the decreased $\mathrm{S}_{1}-\mathrm{T}_{2}$ adiabatic energy gap in water as compared to vacuum. ${ }^{23}$

For selenine, the $\mathrm{S}_{1}\left(\pi_{\mathrm{H}} \pi_{\mathrm{L}}^{*}\right) \rightsquigarrow \rightarrow \mathrm{T}_{2}\left(\pi_{\mathrm{H}-1} \pi_{\mathrm{L}}^{*}\right)$ channel is as efficient in aqueous solution as in vacuum $\left(k_{\mathrm{ISC}} \sim 10^{10} \mathrm{~s}^{-1}\right.$, see Table 5). Applying the solvent-shift to the energy profiles connecting these states (Fig. 4(e)) causes the crossing point between the $\mathrm{S}_{1}\left(\pi_{\mathrm{H}} \pi_{\mathrm{L}}{ }^{*}\right)$ and $\mathrm{T}_{2}\left(\pi_{\mathrm{H}-1} \pi_{\mathrm{L}}{ }^{*}\right)$ states to be slightly shifted towards lower energies. This ISC channel is expected to dominate the photophysics of selenine and effectively quenches the fluorescence in aqueous solution as also seen for thionine.

The calculated rate constant for ISC between the $\mathrm{S}_{2}\left(\pi_{\mathrm{H}-1} \pi_{\mathrm{L}}^{*}\right)$ and $\mathrm{T}_{1}\left(\pi_{\mathrm{H}} \pi_{\mathrm{L}}^{*}\right)$ states in water is just slightly smaller than in vacuum. As shown in Fig. $4(\mathrm{f})$, the hydration effects also affect the location of the $\mathrm{T}_{1}\left(\pi_{\mathrm{H}} \pi_{\mathrm{L}}^{*}\right)-\mathrm{T}_{2}\left(\pi_{\mathrm{H}-1} \pi_{\mathrm{L}}^{*}\right)$ conical intersection, placing it at lower energies and nearer to the $S_{2}\left(\pi_{\mathrm{H}-1} \pi_{\mathrm{L}}^{*}\right)$ minimum. This behaviour compensates the effect of the considerably larger adiabatic energy gap between the $\mathrm{S}_{2}\left(\pi_{\mathrm{H}-1} \pi_{\mathrm{L}}^{*}\right)$ and $\mathrm{T}_{1}\left(\pi_{\mathrm{H}} \pi_{\mathrm{L}}{ }^{*}\right)$ states in water as compared to vacuum (see Table 5). Nevertheless, the rate constants for the remaining $S_{2} m \rightarrow T_{1,2}$ ISC channels are determined to be larger $\left(k_{\mathrm{ISC}} \sim 10^{9} \mathrm{~s}^{-1}\right)$ than fluorescence $\left(k_{\mathrm{F}} \sim 10^{8} \mathrm{~s}^{-1}\right)$.

\section{Summary and conclusions}

New theoretical insights on the effects of oxygen (oxonine, $\mathrm{X}=\mathrm{O}$ ) and selenium (selenine, $\mathrm{X}=\mathrm{Se}$ ) substitution on the 
photophysics of thionine $(\mathrm{X}=\mathrm{S})$ have been presented in this work. We have performed a systematic analysis of the electronic properties of low-lying singlet/triplet excited states of isolated oxonine and selenine. Hydration effects were taken into account using models consisting of the dye-water clusters $\left(\mathrm{OXH}^{+} 3 \mathrm{Wa}\right.$ and $\mathrm{SEH}^{+} 3 \mathrm{Wa}$ ) embedded in a COSMO environment.

The heavy atom effect in the series of dyes under investigation has consequences for the adiabatic energies of the excited states affecting the number of energetically available ISC channels. As the electronic structure of the excited states of these dyes suggests, vibronic spin-orbit coupling (SOC) induces ISC pathways between $\pi \pi^{*}$ states. The heavy atom effects on the direct SOC (which contributes to accelerate these processes) are less evident. Going from oxonine to selenine, the derivatives of the SOC matrix elements calculated upon elongations along the out-of-plane normal modes increase, due to a more efficient mixing of the $\pi \pi^{*}$ and the low-lying $n \pi^{*}$ excited states.

A detailed interpretation of the radiative and radiationless channels is presented. After population of the $S_{1}\left(\pi_{H} \pi_{L}^{*}\right)$ excited state by irradiation with visible light, different decay pathways were found, whose rates depend on the heavy atom substitution $(\mathrm{X}=\mathrm{O}, \mathrm{S}, \mathrm{Se})$. Fluorescence is the major relaxation channel for photoexcited oxonine $\left(k_{\mathrm{F}}=2 \times 10^{8} \mathrm{~s}^{-1}\right)$ in aqueous environment. In thionine and selenine, it is the ISC decay which dominates the photophysical kinetics. In our previous work, ${ }^{23}$ the $S_{1}\left(\pi_{\mathrm{H}} \pi_{\mathrm{L}}^{*}\right) \leadsto \mathrm{T}_{2}\left(\pi_{\mathrm{H}-1} \pi_{\mathrm{L}}^{*}\right)$ ISC channel explains the efficient ISC decay of thionine, which is more efficient in water $\left(k_{\mathrm{ISC}} \sim 10^{9} \mathrm{~s}^{-1}\right)$ than in vacuum $\left(k_{\mathrm{ISC}} \sim 10^{8} \mathrm{~s}^{-1}\right)$.

Selenine has a more complex photophysics, where different trends are found in vacuum and in aqueous solution. In both cases the $S_{1}\left(\pi_{\mathrm{H}} \pi_{\mathrm{L}}^{*}\right)$ and $\mathrm{S}_{2}\left(\pi_{\mathrm{H}-1} \pi_{\mathrm{L}}{ }^{*}\right)$ excited states are found to be adiabatically isoenergetic and the $\mathrm{T}_{1}\left(\pi_{\mathrm{H}} \pi_{\mathrm{L}}{ }^{*}\right)$ and $\mathrm{T}_{2}\left(\pi_{\mathrm{H}-1} \pi_{\mathrm{L}}{ }^{*}\right)$ states are available for ISC. The population of the $S_{2}\left(\pi_{\mathrm{H}-1} \pi_{\mathrm{L}}{ }^{*}\right)$ excited state of selenine is found to be energetically feasible via $S_{1} \rightsquigarrow S_{2}$ internal conversion (IC). In vacuum, we found two fast ISC pathways: the $S_{1}\left(\pi_{\mathrm{H}} \pi_{\mathrm{L}}{ }^{*}\right) \rightsquigarrow \rightarrow T_{2}\left(\pi_{\mathrm{H}-1} \pi_{\mathrm{L}}{ }^{*}\right)$ and the $\mathrm{S}_{2}\left(\pi_{\mathrm{H}-1} \pi_{\mathrm{L}}{ }^{*}\right) \rightsquigarrow \mathrm{T}_{1}\left(\pi_{\mathrm{H}} \pi_{\mathrm{L}}{ }^{*}\right)$ channels with computed rate constants of the order of $k_{\text {ISC }} \sim 1 \times 10^{10} \mathrm{~s}^{-1}$, which are faster than fluorescence decay $\left(k_{\mathrm{F}}=1.59 \times 10^{8} \mathrm{~s}^{-1}\right)$. Other less efficient ISC channels were also found to be faster $\left(k_{\mathrm{ISC}} \sim 10^{9} \mathrm{~s}^{-1}\right)$ than fluorescence. In aqueous solution, the energetic splitting of the $\mathrm{S}_{2}\left(\pi_{\mathrm{H}-1} \pi_{\mathrm{L}}{ }^{*}\right)$ and $\mathrm{T}_{1}\left(\pi_{\mathrm{H}} \pi_{\mathrm{L}}{ }^{*}\right)$ excited states is predicted to be larger than in vacuum. As a consequence, the $S_{2}\left(\pi_{\mathrm{H}-1} \pi_{\mathrm{L}}^{*}\right) \rightsquigarrow \rightarrow$ $\mathrm{T}_{1}\left(\pi_{\mathrm{H}} \pi_{\mathrm{L}}^{*}\right)$ ISC rate constant is decreased to $k_{\mathrm{ISC}} \sim 10^{9} \mathrm{~s}^{-1}$ and is no longer the prominent channel. This suggests that the radiationless deactivation via $\mathrm{S}_{1}\left(\pi_{\mathrm{H}} \pi_{\mathrm{L}}{ }^{*}\right) \rightsquigarrow \mathrm{T}_{2}\left(\pi_{\mathrm{H}-1} \pi_{\mathrm{L}}{ }^{*}\right)$ ISC dominates the population of the triplet manifold of selenine in aqueous solution $\left(k_{\mathrm{ISC}}=3 \times 10^{10} \mathrm{~s}^{-1}\right)$. All of these radiationless channels (IC and ISC), which are faster than fluorescence, eventually lead to an efficient population of the triplet manifold in selenine.

Due to the heavy atom effect which is indirectly increasing the vibronic spin-orbit coupling between the $\pi \pi^{*}$ electronic states, the radiationless transitions are accelerated in the series from $\mathrm{X}=\mathrm{O}$ to $\mathrm{X}=$ Se. Within the limitations of the computational models used in this work, the qualitative picture obtained here is in very good agreement with the experimental data reported for oxonine and thionine. This validates our computational model and the conclusions derived therefrom, allowing us to classify selenine-based dyes to be very efficient triplet photosensitizers.

\section{Acknowledgements}

A.R.-S. thanks Dr J. Tatchen for helpful discussions. The financial support from COLCIENCIAS (Conv. 494), Universidad Industrial de Santander (project 1400) and Deutsche Forschungsgemeinschaft through MA 1052/12-1 is gratefully acknowledged.

\section{References}

1 M. Wainwright and R. M. Giddens, Dyes Pigm., 2003, 57, 245-257.

2 M. Wainwright, Photosensitisers in Biomedicine, John Wiley \& Sons Ltd, Chichester, UK, 2009.

3 S. I. Zacks, Ann. Clin. Lab. Sci., 1975, 5, 161-166.

4 M. Wainwright, H. Mohr and W. H. Walker, J. Photochem. Photobiol., B, 2007, 86, 45-58.

5 K. Tanaka, S. Ikeda, N. Oyama, K. Tokuda and T. Ohsaka, Anal. Sci., 1993, 9, 783-789.

6 S. Preus, K. Kilså, L. M. Wilhelmsson and B. Albinsson, Phys. Chem. Chem. Phys., 2010, 12, 8881-8892.

7 M. Wainwright, Int. J. Antimicrob. Agents, 2000, 16, 381-394.

8 J. P. Tardivo, A. Del Giglio, C. Santos de Oliveira, D. Santesso Gabrielli, H. Couto Junqueira, D. Batista Tadab, D. Severino, R. de Fatima Turchiello and M. S. Baptista, Photodiagn. Photodyn. Ther., 2005, 2, 175-191.

9 D. Gabrielli, E. Belisle, D. Severino, A. J. Kowaltowski and M. S. Baptista, Photochem. Photobiol., 2004, 79, 227-232.

10 D. Dolmans, D. Fukumura and R. K. Jain, Nat. Rev. Cancer, 2003, 3, 380-387.

11 L. M. Moreira, J. P. Lyon, A. P. Romani, D. Severino, M. R. Rodrigues and H. P. M. Oliveira, in Advanced Aspects of Spectroscopy, ed. M. A. Farrukh, InTech, 2012, ch. 14.

12 M. A. Houghtaling, R. Perera, K. E. Owen, S. Wagner, R. J. Kuhn and H. Morrison, Photochem. Photobiol., 2000, 71, 20-28.

13 T. Y. Ohulchanskyy, D. J. Donnelly, M. R. Detty and P. N. Prasad, J. Phys. Chem. B, 2004, 108, 8668-8672.

14 L. Cincotta, J. W. Foley and A. H. Cincotta, Cancer Res., 1993, 53, 2571-2580.

15 Y. Usui, Chem. Lett., 1973, 743-744.

16 M. Wainwright, Photodiagn. Photodyn. Ther., 2005, 2, 263-272.

17 E. Vogelmann and H. E. A. Kramer, Photochem. Photobiol., 1976, 23, 383-390.

18 N. Gfeller, S. Megelski and G. Calzaferri, J. Phys. Chem. B, 1999, 103, 1250-1257.

19 D. Creed, N. C. Fawcett and R. L. Thompson, Photochem. Photobiol., 1991, 53, 573-586. 
20 U. Steiner, G. Winter and H. E. A. Kramer, J. Phys. Chem., 1977, 81, 1104-1110.

21 X. Song, D. S. Kassaye and J. W. Foley, J. Fluoresc., 2008, 18, 513-518.

22 A. Rodriguez-Serrano, M. C. Daza, M. Doerr and C. M. Marian, Photochem. Photobiol. Sci., 2012, 11, 397-408.

23 A. Rodriguez-Serrano, V. Rai-Constapel, M. C. Daza, M. Doerr and C. M. Marian, Photochem. Photobiol. Sci., 2012, 11, 1860-1867.

24 F. Furche and R. Ahlrichs, J. Chem. Phys., 2002, 117, 7433.

25 A. D. Becke, J. Chem. Phys., 1993, 98, 5648.

26 P. A. M. Dirac, Proc. R. Soc. London, Ser. A, 1929, 123, 714-733.

27 TURBOMOLE V6.3 2011, a development of University of Karlsruhe and Forschungszentrum Karlsruhe $\mathrm{GmbH}$, 1989-2007, TURBOMOLE GmbH, since 2007.

28 C. Kind, M. Reiher and J. Neugebauer, SNF Version 2.2.1: A Program Package for Numerical Frequency Analyses, Universität Erlangen, 1999-2002.

29 A. Schäfer, C. Huber and R. Ahlrichs, J. Chem. Phys., 1994, 100, 5829.

30 S. Grimme and M. Waletzke, J. Chem. Phys., 1999, 111, 5645.

31 C. M. Marian and N. Gilka, J. Chem. Theory Comput., 2008, 4, 1501-1515.

32 M. R. Silva-Junior, M. Schreiber, S. P. A. Sauer and W. Thiel, J. Chem. Phys., 2008, 128, 104103.

33 A. Klamt and G. Schüürmann, J. Chem. Soc., Perkin Trans. 2, 1993, 799-805.
34 A. Schäfer, A. Klamt, D. Sattel, J. C. W. Lohrenz and F. Eckert, Phys. Chem. Chem. Phys., 2000, 2, 2187-2193.

35 C. Reichardt, Solvents and Solvent Effects in Organic Chemistry, Wiley-VCH, Weinheim, Germany, 1990.

36 M. Kleinschmidt, J. Tatchen and C. M. Marian, J. Chem. Phys., 2011, 124, 124101.

37 M. Kleinschmidt, J. Tatchen and C. M. Marian, J. Comput. Chem., 2002, 23, 824-833.

38 B. A. Heß, C. M. Marian, U. Wahlgren and O. Gropen, Chem. Phys. Lett., 1996, 251, 365-371.

39 J. Tatchen, N. Gilka and C. M. Marian, Phys. Chem. Chem. Phys., 2007, 9, 5209-5221.

40 B. Minaev and H. Ågren, Chem. Phys., 2005, 315, 215-239.

41 M. Etinski, V. Rai-Constapel and C. M. Marian, J. Chem. Phys., 2014, 140, 114104.

42 M. Etinski, J. Tatchen and C. M. Marian, J. Chem. Phys., 2011, 134, 154105.

43 M. Etinski, J. Tatchen and C. M. Marian, Phys. Chem. Chem. Phys., 2014, 16, 4740-4751.

44 L. F. Epstein, F. Karush and A. Rabinowitch, J. Opt. Soc. Am., 1941, 31, 77-84.

45 J. Qiang Wu, D. Baumann and U. E. Steiner, Mol. Phys., 1995, 84, 981-994.

46 E. Vogelmann, H. Schmidt, U. Steiner and H. E. A. Kramer, Z. Phys. Chem., 1975, 94, 101-106.

47 G. W. Robinson, in Excited States, ed. E. C. Lim, Academic Press Inc., London, 1974, vol. 1, pp. 1-34. 